\title{
Review
}

\section{The diagnosis and management of pre-invasive breast disease Problems associated with management of pre-invasive lesions} Anand D Purushotham

\author{
Cambridge Breast Unit, Addenbrooke's NHS Trust, Cambridge, UK \\ Corresponding author: Anand D Purushotham (e-mail: amy.byrtus@addenbrookes.nhs.uk) \\ Published: 9 October 2003 \\ Breast Cancer Res 2003, 5:309-312 (DOI 10.1186/bcr649) \\ (C) 2003 BioMed Central Ltd (Print ISSN 1465-5411; Online ISSN 1465-542X)
}

\begin{abstract}
The treatment of ductal carcinoma in situ (DCIS) involves adequate surgical excision with adjuvant radiotherapy where appropriate. An inadequate excision margin and young age are independent risk factors for local recurrence. Routine surgery to axillary lymph nodes is not recommended in pure DCIS. In localised DCIS, adjuvant radiotherapy is recommended on the basis of tumour size, margin width and pathological subtypes. The role of adjuvant tamoxifen as systemic therapy is controversial. The treatment of atypical ductal/lobular hyperplasia and lobular carcinoma in situ involves surgical excision to exclude coexisting DCIS or invasive disease.
\end{abstract}

Keywords: breast, management, pre-invasive disease

\section{Surgical management of ductal carcinoma in situ (DCIS)}

The primary treatment of DCIS is based on the extent of DCIS in the breast.

Widespread DCIS (Fig. 1) is treated by mastectomy with excision of the nipple areola complex with or without immediate or delayed reconstruction using prosthetic or autogenous tissue techniques. Where immediate breast reconstruction is performed, a skin-sparing mastectomy is preferred. Mastectomy results in the removal of most of the breast tissue with a low local recurrence rate and excellent survival.

Localised DCIS is treated by wire-guided localisation and wide local excision followed by adjuvant therapy if appropriate. Surgical excision should ideally follow the segmental anatomy of the breast, and it is crucial to ensure an 'adequate' radial excision margin. Intra-operatively, in the presence of microcalcification, a specimen radiograph of the excised tissue, with appropriate orientation of the specimen, will provide an initial guide to adequacy of excision (Fig. 2). It is important to place marker sutures and metallic clips to orientate the specimen accurately. If the specimen X-ray demonstrates the presence of microcalcification close to one or more radial margins, further excision of the margin(s) in question can be performed immediately. In many cases this will obviate the need for a second procedure.

Local protocols agreed by the multidisciplinary team will ensure accurate interpretation of the results of histopathology, thereby facilitating subsequent treatment decisions. Occasionally the extent of DCIS is underestimated radiologically and further surgery may be required on the basis of the results of histopathology [1]. In some situations, it may be possible to remove relatively large areas of DCIS and preserve the breast by performing oncoplastic procedures.

\section{Margin of excision}

DCIS is a potentially curable disease. 'Adequate' surgical excision is required, to minimise the risk of local recurrence. Data from several studies demonstrate that approximately half of all local recurrences will be invasive carcinoma [2-4]. There is currently no consensus on what constitutes an 'adequate' margin of excision. The margin of excision can be described as 'involved' or 'close' or 
Figure 1

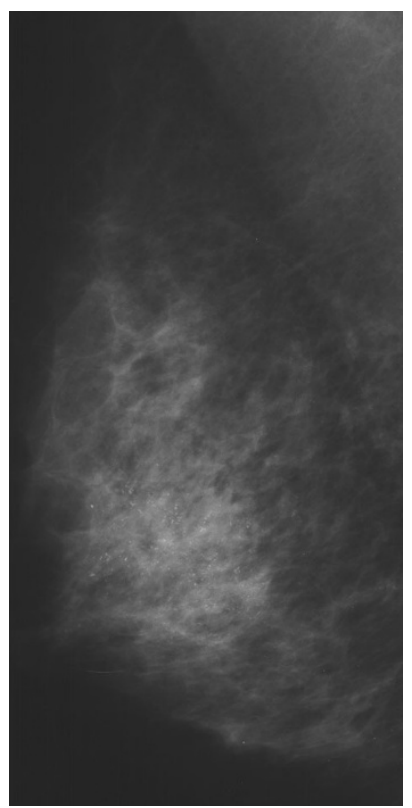

Mammogram demonstrating widespread ductal carcinoma in situ.

defined in terms of distance in millimetres between diseased and normal breast tissue. The consensus view recommends a second re-excision where a margin is involved. Mastectomy may be indicated where there is extensive DCIS close to several margins, indicating an initial underestimate of the extent of the disease in the breast, because the extent of DCIS does not always correspond to the extent of microcalcification. A study examining the width of excision margin, in patients undergoing breast-conserving surgery (BCS) with or without radiotherapy for DCIS, demonstrated a significantly higher local recurrence rate in patients with a final excision margin of $1 \mathrm{~mm}$ or less than in those with a margin of more than $1 \mathrm{~mm}$ [5]. This is hardly surprising given that DCIS, like invasive carcinoma, does not have a concentric distribution, and the reason for the reported higher local recurrence might be related to a failure to achieve complete excision of existing disease. Further evidence exists in the literature for the benefit of achieving a minimum excision margin of $10 \mathrm{~mm}$ in patients with DCIS. In a series of 342 patients undergoing BCS with or without radiotherapy for localised DCIS, an excision margin of $10 \mathrm{~mm}$ or more with adjuvant radiotherapy achieved a non-significant reduction of $8 \%$ in local recurrence in the high-grade DCIS group [6]. However, this excision margin might be excessive because this does not take into account the fact that DCIS, like invasive disease, is heterogeneous and cases of low-grade and intermediate-grade DCIS might not require this extent of excision, notwithstanding the benefit
Figure 2

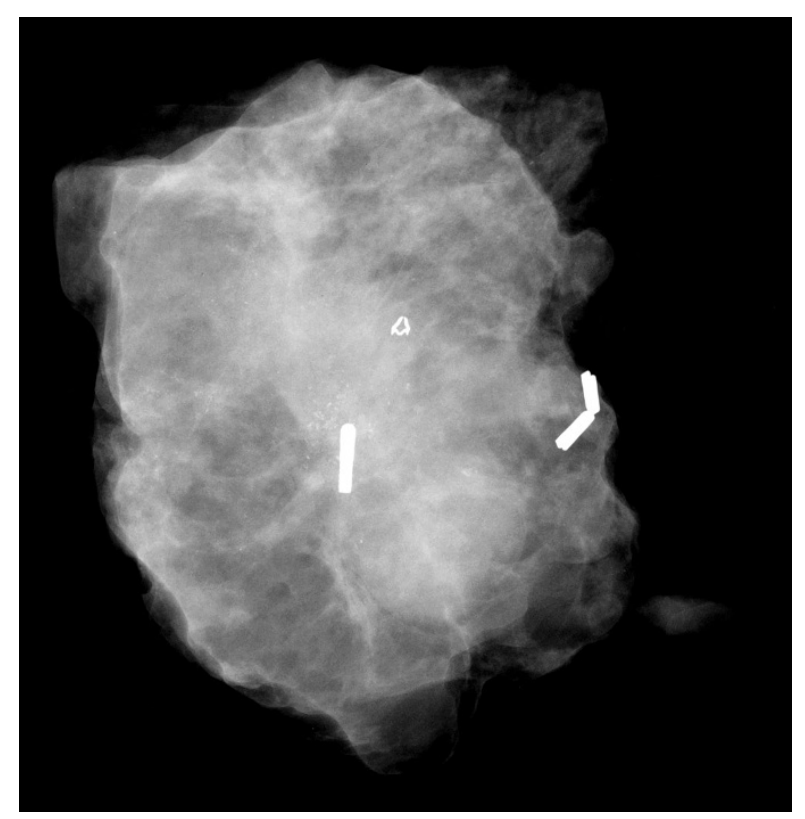

Specimen radiograph after wide local excision for localised ductal carcinoma in situ, demonstrating microcalcification in the centre of the specimen with marker clips for orientation. The additional titanium clip visible is that inserted after mammotome core biopsy.

of what constitutes an 'adequate' margin of excision, it is important that individual institutions adopt appropriate local protocols and evaluate their longer-term results, amending these protocols as further evidence on adequacy of surgical excision margins emerges in the literature.

\section{Other factors influencing surgical treatment Age}

Some studies have examined the influence of younger age on local recurrence and prognosis in patients with DCIS. Experience from North America and Europe has shown that younger age is associated with a higher rate of local recurrence. In a series of 422 patients undergoing BCS and adjuvant radiotherapy with a mean follow-up of 9.4 years, local recurrence relative to patient age was $31 \%$ in patients aged less than 40 years, $13 \%$ in the 40-49-year age group, $8 \%$ in the 50-59-year age group and $6 \%$ in patients aged more than 60 years. On multivariate analysis, an age of less than 40 years was shown to be an independent factor for local recurrence [7]. Similar findings were described by the French Cancer Centers in 515 patients undergoing BCS and radiotherapy for DCIS. At a mean follow-up of 7 years, the local recurrence rate relative to patient age was $29 \%$ in patients less than 40 years of age, $13 \%$ in patients aged $41-60$ years and $8 \%$ in patients aged more than 61 years. On multivariate analysis, younger age was found to be an independent prognostic factor for local recurrence [4]. A recent review 
indicates that younger age is associated with more widespread DCIS, more adverse pathological prognostic factors, higher local recurrence rate and rate of invasive recurrence, and worse prognosis [8].

\section{Family history of breast cancer}

Two small series of patients treated for DCIS have shown a higher local recurrence rate in patients with a family history of breast cancer. These studies require confirmation $[9,10]$.

Despite the above data, it would be premature to recommend more radical surgical treatment for patients with localised DCIS that can be treated by BCS on the basis of the extent of the disease within the breast. It might be more appropriate to recommend adjuvant radiotherapy in this subgroup of patients to minimise the risk of local recurrence.

\section{Axillary lymph node surgery}

As a general guidance, axillary lymph node clearance is not required if the disease is pure DCIS with no evidence of invasion. This might be reserved for patients in whom subsequent final histopathology demonstrates invasive disease in the excision specimen. Surgical care needs to be exercised in patients who have undergone immediate breast reconstruction, especially if the latissimus dorsi flap has been used for this purpose.

With the advent of sentinel-node biopsy in breast cancer, reports have emerged in the literature of its value in DCIS. Using a combination of conventional serial sectioning, haematoxylin/eosin staining and immunohistochemistry, a $6-13 \%$ rate of positive sentinel nodes was detected in patients with proven DCIS and no evidence of invasion [11-13]. The above findings should be interpreted with caution because the relevance of axillary micrometastasis in determining prognosis in invasive breast cancer remains controversial.

\section{Adjuvant radiotherapy}

The role of adjuvant radiotherapy after BCS in the management of DCIS has been examined in randomised trials. In the NSABP-B17 study, at a mean follow-up of 7.5 years, the benefit of lumpectomy plus radiation was demonstrated by a reduction in the incidence of ipsilateral non-invasive breast recurrence from $13.4 \%$ to $8.2 \%$ and of ipsilateral invasive breast recurrence from $13.4 \%$ to $3.9 \%$ [2]. In the EORTC randomised phase III trial 10853, the benefit of adjuvant radiotherapy was demonstrated by a reduction in local recurrence from $17 \%$ (wide local excision) to $10 \%$ (wide local excision plus radiotherapy) [3]. The results of this trial have been recently debated on the basis of patient selection for entry into the trial. The authors suggest that as a result, the findings of this trial might not be applicable to all patients with DCIS [14].
Until further confirmation of the benefit of radiotherapy in subgroups of patients with DCIS have been confirmed, a pragmatic approach might be to apply the Van Nuys Prognostic Index, which relies on tumour size, margin width, and pathological classification in recommending adjuvant radiotherapy to selected patients with DCIS [15].

\section{Role of tamoxifen in DCIS}

In the NSABP-B24 randomised trial examining the benefit of adjuvant tamoxifen in women undergoing BCS and radiotherapy for localised DCIS, patients in the tamoxifen group had fewer breast-cancer events at 5 years than did those on placebo (8.2\% versus $13.4 \%$ ) [16]. This benefit of tamoxifen might be attributed to its chemopreventive effect as demonstrated in two randomised trials: the P1 and IBIS trials [17,18]. However, this effect was not demonstrated in two other trials $[19,20]$. If this finding of the chemopreventive effect of tamoxifen in women at increased risk of breast cancer is accepted, then it would not be unreasonable to consider women with a history of DCIS for such therapy [21].

\section{Surgical management of core biopsies showing atypical ductal/lobular hyperplasia and lobular carcinoma in situ}

A preoperative diagnosis on core biopsy of atypical ductal hyperplasia, atypical lobular hyperplasia or lobular carcinoma in situ indicates the possibility of a $14-21 \%$ incidence of associated DCIS or invasive carcinoma [22-25]. The role of surgery is therefore to rule out this possibility. Surgical excision is performed by guidewire localisation with adequate specimen orientation. If further excision shows the presence of DCIS or invasive carcinoma, this lesion is treated on its own merits. If further excision shows no evidence of further disease, a mammography screening programme can be set up whose frequency is as yet unclear. Current surgical consensus does not advocate mastectomy in the management of these patients. However, in the presence of a strong family history of breast cancer, prophylactic mastectomy may be discussed on the basis of the merits of the family history and the patient supported in her decision. In view of the results of the P1 and IBIS studies, it might be worth also considering the option of chemoprevention with tamoxifen in this group of patients $[17,18]$.

This article is the seventh in a review series on The diagnosis and management of pre-invasive breast disease - current challenges, future hopes, edited by Sunil R Lakhani.

Other articles in the series can be found at http://breast-cancer-research.com/articles/reviewseries.asp?series=bcr_Thediagnosis 


\section{Competing interests}

None declared.

\section{References}

1. Holland $\mathrm{R}$, Veling $\mathrm{SH}$, Mravunac M, Hendriks JH: Histologic multifocality of Tis, T1-2 breast carcinomas. Implications for clinical trials of breast-conserving surgery. Cancer 1985, 56: 979-990.

2. Fisher B, Dignam J, Wolmark N, Mamounas E, Costantino J, Poller W, Fisher ER, Wickerham DL, Deutsch M, Margolese R, Dimitrov $\mathrm{N}$, Kavanah $\mathrm{M}$ : Lumpectomy and radiation therapy for the treatment of intraductal breast cancer: findings from National Surgical Adjuvant Breast and Bowel Project B-17. J Clin Oncol 1998, 16:441-452.

3. Julien JP, Bijker N, Fentiman IS, Peterse JL, Delledonne V, Rouanet P, Avril A, Sylvester R, Mignolet F, Bartelink H, Van Dongen JA: Radiotherapy in breast-conserving treatment for ductal carcinoma in situ: first results of the EORTC randomised phase III trial 10853. EORTC Breast Cancer Cooperative Group and EORTC Radiotherapy Group. Lancet 2000, 355:528-533.

4. Cutuli B, Cohen-Solal-le Nir C, de Lafontan B, Mignotte H, Fichet V, Fay R, Servent V, Giard S, Charra-Brunaud C, Lemanski C, Auvray $\mathrm{H}$, Jacquot $\mathrm{S}$, Charpentier JC: Breast-conserving therapy for ductal carcinoma in situ of the breast: the French Cancer Centers' experience. Int J Radiat Oncol Biol Phys 2002, 53: 868-879.

5. Chan KC, Knox WF, Sinha G, Gandhi A, Barr L, Baildam AD, Bundred $\mathrm{NJ}$ : Extent of excision margin width required in breast conserving surgery for ductal carcinoma in situ. Cancer 2001, 91:9-16.

6. Lagios MD, Silverstein MJ: Ductal carcinoma in situ. The success of breast conservation therapy: a shared experience of two single institutional nonrandomized prospective studies. Surg Oncol Clin N Am 1997, 6:385-392.

7. Solin LJ, Fourquet A, Vicini FA, Haffty B, Taylor M, McCormick B, McNeese M, Pierce LJ, Landmann C, Olivotto IA, Borger J, Kim J, de la Rochefordiere A, Schultz DJ: Mammographically detected ductal carcinoma in situ of the breast treated with breast-conserving surgery and definitive breast irradiation: long-term outcome and prognostic significance of patient age and margin status. Int J Radiat Oncol Biol Phys 2001, 50:991-1002.

8. Vicini FA, Recht A: Age at diagnosis and outcome for women with ductal carcinoma-in-situ of the breast: a critical review of the literature. J Clin Oncol 2002, 20:2736-2744.

9. Szelei-Stevens KA, Kuske RR, Yantsos VA, Cederbom GJ, Bolton JS, Fineberg BB: The influence of young age and positive family history of breast cancer on the prognosis of ductal carcinoma in situ treated by excision with or without radiation therapy or by mastectomy. Int J Radiat Oncol Biol Phys 2000, 48:943-949.

10. Hiramatsu H, Bornstein BA, Recht A, Schnitt SJ, Baum JK, Connolly JL, Duda RB, Guidi AJ, Kaelin CM, Silver B, Harris JR: Local recurrence after conservative surgery and radiation therapy for ductal carcinoma in situ: possible importance of family history. Cancer J Sci Am 1995, 1:55-61.

11. Cox CE, Nguyen K, Gray RJ, Salud C, Ku NN, Dupont E, Hutson L, Peltz E, Whitehead G, Reintgen D, Cantor A: Importance of lymphatic mapping in ductal carcinoma in situ (DCIS): why map DCIS? Am Surg 2001, 67:513-519.

12. Klauber-DeMore N, Tan LK, Liberman L, Kaptain S, Fey J, Borgen P, Heerdt A, Montgomery L, Paglia M, Petrek JA, Cody HS, Van Zee KJ: Sentinel lymph node biopsy: is it indicated in patients with high-risk ductal carcinoma-in-situ and ductal carcinomain-situ with microinvasion? Ann Surg Oncol 2000, 7:636-642.

13. Pendas S, Dauway E, Giuliano R, Ku N, Cox CE, Reintgen DS: Sentinel node biopsy in ductal carcinoma in situ patients. Ann Surg Oncol 2000, 7:15-20.

14. Bijker N, Peterse JL, Fentiman IS, Julien JP, Hart AA, Avril A, Cataliotti L, Rutgers EJ: Effects of patient selection on the applicability of results from a randomised clinical trial (EORTC 10853) investigating breast-conserving therapy for $\mathrm{DCIS} . \mathrm{Br} J$ Cancer 2002, 87:615-620.

15. Silverstein MJ, Lagios MD, Craig PH, Waisman JR, Lewinsky BS, Colburn WJ, Poller DN: A prognostic index for ductal carcinoma in situ of the breast. Cancer 1996, 77:2267-2274.
16. Fisher B, Dignam J, Wolmark N, Wickerham DL, Fisher ER, Mamounas E, Smith R, Begovic M, Dimitrov NV, Margolese RG, Kardinal CG, Kavanah MT, Fehrenbacher L, Oishi RH: Tamoxifen in treatment of intraductal breast cancer: National Surgical Adjuvant Breast and Bowel Project B-24 randomised controlled trial. Lancet 1999, 353:1993-2000.

17. Fisher B, Costantino JP, Wickerham DL, Redmond CK, Kavanah M, Cronin WM, Vogel V, Robidoux A, Dimitrov N, Atkins J, Daly M, Wieand S, Tan-Chiu E, Ford L, Wolmark N: Tamoxifen for prevention of breast cancer: report of the National Surgical Adjuvant Breast and Bowel Project P-1 Study. J Natl Cancer Inst 1998, 90:1371-1388.

18. IBIS investigators: First results from the International Breast Cancer Intervention Study (IBIS-I): a randomised prevention trial. Lancet 2002, 360:817-824.

19. Powles T, Eeles R, Ashley S, Easton D, Chang J, Dowsett M, Tidy A, Viggers J, Davey J: Interim analysis of the incidence of breast cancer in the Royal Marsden Hospital tamoxifen randomised chemoprevention trial. Lancet 1998, 352:98-101.

20. Veronesi U, Maisonneuve P, Costa A, Sacchini V, Maltoni C, Robertson C, Rotmensz N, Boyle P: Prevention of breast cancer with tamoxifen: preliminary findings from the Italian randomised trial among hysterectomised women. Italian Tamoxifen Prevention Study. Lancet 1998, 352:93-97.

21. Fisher B, Land S, Mamounas E, Dignam J, Fisher ER, Wolmark N: Prevention of invasive breast cancer in women with ductal carcinoma in situ: an update of the national surgical adjuvant breast and bowel project experience. Semin Oncol 2001, 28: 400-418.

22. Tocino I, Garcia BM, Carter D: Surgical biopsy findings in patients with atypical hyperplasia diagnosed by stereotaxic core needle biopsy. Ann Surg Oncol 1996, 3:483-488.

23. Renshaw AA, Cartagena N, Schenkman RH, Derhagopian RP, Gould EW: Atypical ductal hyperplasia in breast core needle biopsies. Correlation of size of the lesion, complete removal of the lesion, and the incidence of carcinoma in follow-up biopsies. Am J Clin Pathol 2001, 116:92-96.

24. Shin SJ, Rosen PP: Excisional biopsy should be performed if lobular carcinoma in situ is seen on needle core biopsy. Arch Pathol Lab Med 2002, 126:697-701.

25. Jacobs TW, Connolly JL, Schnitt SJ: Nonmalignant lesions in breast core needle biopsies: to excise or not to excise? Am J Surg Pathol 2002, 26:1095-1110.

\section{Correspondence}

Anand D Purushotham, Cambridge Breast Unit, Box 97, Addenbrooke's NHS Trust, Hills Road, Cambridge CB2 2QQ, UK. Tel: +1 1223 586627; fax +1 1223 257219; e-mail: amy.byrtus@addenbrookes.nhs.uk 